IP Periodica Polytechnica

Social and Management

Sciences

24(1), pp. 60-64, 2016

DOI: $10.3311 /$ PPso. 8158

Creative Commons Attribution (i)

RESEARCH ARTICLE

\section{Evaluation of Flood Losses to Buildings: Effect of Room Dimensions}

\author{
Martin Tuscher ${ }^{1}$, Tomas Hanak ${ }^{1 *}$
}

Received 16 April 2015; accepted 22 May 2015

\begin{abstract}
Currently, the use of loss curves is largely limited, since they are usually based only on a few selected parameters. As a result, the amount of estimated losses may not fully correspond to the real costs of restoring the building to its original condition. The aim of the presented research is to determine whether the factor of room dimensions has a significant effect on the amount of unit flood loss on a building.

It has been found that this effect may have a significant impact on the evaluation of flood loss on the level of a single room using loss curves. Therefore, it is concluded that this issue should be examined further to establish its significance on the level of whole buildings in order to increase the accuracy of flood loss evaluations carried out by insurance companies.
\end{abstract}

\section{Keywords}

building, evaluation, flood, loss, room dimension
${ }^{1}$ Institute of Structural Economics and Management,

Faculty of Civil Engineering,

Brno University of Technology

*Corresponding author, e-mail: hanak.t@fce.vutbr.cz

\section{Introduction}

The increased frequency of extreme hydrological events and the need for a quick evaluation of flood loss after large-scale events brings the need for a tool that would make it possible to evaluate the amount of loss on a given building quickly and with an acceptable degree of inaccuracy. This approach allows for a quicker payment (or at least partial payment) of the insurance claim, thus making the work of the insurance claim adjusters more efficient and saving both time and related costs. Unfortunately, loss curves cannot take into account all the factors that influence the amount of loss and are therefore often based solely on the flood depth parameter. The objective of this paper is to analyse another factor that might have an impact on the accuracy of loss evaluation. Specifically, this research aims to assess the significance of the impact of room dimensions in residential buildings - in particular the impact of room areas and shapes - on the amount of unit loss per $1 \mathrm{~m}^{2}$ of floor area.

The paper is structured as follows: first, the research background is introduced, followed by methodology. The next section of the paper presents the results of the research and the related discussion. Finally, the conclusion section sums up the results of the research, as well as noting research limitations and future research directions.

\section{Research Background}

Floods are one of natural hazards and can be described by a number of parameters, such as depth of flood, duration of flooding or flow velocity. It is difficult to clearly determine whether a parameter is significant or not, as the amount of potential loss is influenced not only the condition of the structure, but also by its type (road, railway, residential building, manufacturing facility, etc.) and its structural and material specifications. For example, it has been found that flow velocity has a significant impact on the amount of flood loss in the case of structural damage to roads; however, in the case of damage to residential buildings, the impact is strong only if the flow velocity exceeds a certain critical level (Kreibich et al., 2009). The type of flood must also be taken into account (river flooding, lake flooding, coastal flooding, flash floods, etc.). In the case of lake floods, Grahn 
and Nyberg (2014) point out that flood duration and wind and wave impact must be taken into account as well as flood depth.

Because this paper focuses solely on residential buildings, it should be mentioned that the range of flood actions on a building is very wide, including hydrostatic, hydrodynamic, erosion, buoyancy, debris and non-physical (e.g. chemical or biological) actions (Kelman and Spence, 2004). These actions cause damage not only to property, but also to the environment; therefore, flood risk management procedures must be applied as well as effective flood mitigation measures (Zeleňáková and Zvijáková, 2014). In the case of residential buildings, building precautionary measures may have a significant positive impact on decreasing flood damage, especially for small-scale floods (Kreibich et al., 2005).

The area of flood management and zoning has been studied in some detail, see e.g. (Jiang et al., 2009; Tingsanchali and Karim, 2010), but specific risks are still being developed in certain countries, such as the issue of coastal risk mapping and coastal zone management in Croatia (Ružić et al., 2014).

Prediction and evaluation of flood damage grows in importance in relation to the global climate change. Hattermann et al. (2014) argue that climate change will cause the occurrence of more hydrological extremes that will go together with larger and more serious losses. In effect, this can have a negative impact on the sustainability of private insurance schemes (Jongman et al., 2014).

In the context of insurance, there are two levels of setting the amount of loss: 1) robust estimates of extreme events to model the risk and set loss rates, and 2) evaluation of partial loss on the level of the individual insured persons to calculate the amount of the insurance claim. Aggregate evaluation of losses in a given area is very problematic and requires a large number of data that are burdened with uncertainty (Sampson et al., 2014). Furthermore, there are a number of factors that have an impact on the evaluation of a specific claim and that cause inaccuracies in the results given by loss curves that are used in practice. For example, Elmer et al. (2010) proved a high positive correlation between the flood recurrence interval and scale of loss. If it is taken into account that floods occur repeatedly on certain watercourses (Vivoda et al., 2012), this may have a significant impact on the loss potential of residential buildings in floodplain areas. Moreover, loss curves frequently use only water depth, which results in an inaccurate estimate of the actual loss, as it is influenced by a number of other aspects as well (Merz et al., 2004). Merz et al. highlight the need to classify buildings according to the type of structure (timber structure, concrete building, masonry, etc.).

However, the inaccuracy of loss curves also partially results from the heterogeneity of the data that are used to model them. The authors in (André et al., 2013) therefore highlight the need to standardise the collection of data for the loss adjustment process.

The performed review of literature positively shows that loss curves are not able to adequately account for all the aspects that have an impact on the amount of loss. Nevertheless, the individual factors need to be analysed one by one to determine their significance. If the examined factor proves to be of high significance, it can be included in the loss curves in the future. Similarly, factors that have been empirically proved to be of marginal significance may be excluded. This paper examines the specific question of the significance of the impact of room dimensions in residential buildings on the amount of unit loss.

Increasing risk of floods in urban areas, for example in the context of intensive urbanisation and improper management of flood-prone areas (Glosinska, 2014) results in the need for a more sophisticated risk management not only for the correct delineation of risk zones (Hanák and Korytárová, 2014), but also to determine premium rates that are more accurate in accounting for the amount of potential loss in a given building with regard to its specific parameters.

\section{Methodology}

The following steps were taken to evaluate the significance of the impact of room dimensions in residential buildings on the amount of unit loss (expressed in floor area units). First, buildings were divided into three categories: $\mathrm{A}$ - houses, $\mathrm{B}$ - apartments, $\mathrm{C}$ - common and cellar areas of apartment buildings. Due to the construction and material nature of the research, this paper focuses solely on categories A and B.

Second, representatives of rooms distinguished by floor area and length-to-width ratio were created. All in all, there were 14 room size groups (RG) and specific side dimensions were simulated for each room of a given size. The side ratio (SR) is expressed by the following equation:

$$
\text { SR = length } / \text { width }
$$

The maximum value of $\mathrm{SR}=1$ and the minimum value of a side is $1 \mathrm{~m}$. Altogether, the analysis assessed 422 variants. The examined sample is described in more detail in Table 1.

Afterwards, the construction and material specifications of the examined rooms were determined: the vertical structures consist of a masonry wall with plaster and paint; the horizontal structures consist of a concrete panel and laminate composite flooring.

For the purpose of modelling damage to structures, the parameters of the flood also had to be specified. In this research, the flood was only characterised by depth of flooding; other flood parameters (duration of flooding, flow velocity, etc.) were not taken into account. Depth of flooding was set to $1 \mathrm{~m}$ at this stage of research. The extent of damaged structures is then specified within this context. In the case of floors, the structures in question are the tread layer and baseboards. In the case of walls, they are plaster and paint. This stage of research disregards damage to door wings and frames.

Afterwards, itemised budgets corresponding with the estimated level of damage were developed for the individual variants to determine the costs needed for the repair of damaged 
Table 1 Parameters of the examined sample

\begin{tabular}{|c|c|c|}
\hline Room group by size & Area $\left(\mathrm{m}^{2}\right)$ & Number of various side ratios \\
\hline RG1 & 4 & 11 \\
\hline RG2 & 6 & 15 \\
\hline RG3 & 8 & 19 \\
\hline RG4 & 10 & 22 \\
\hline RG5 & 12 & 25 \\
\hline RG6 & 14 & 28 \\
\hline RG7 & 16 & 31 \\
\hline RG8 & 18 & 33 \\
\hline RG9 & 20 & 35 \\
\hline RG10 & 22 & 37 \\
\hline RG11 & 24 & 39 \\
\hline RG12 & 26 & 41 \\
\hline RG13 & 28 & 43 \\
\hline RG14 & 30 & 45 \\
\hline
\end{tabular}

structures. For the flooding of masonry walls (vertical areas), the budget includes costs of work related to the removal of plaster, high-pressure cleaning and disinfection of the masonry, manual plastering using lime stucco plaster and final surface treatment using two layers of antimicrobial paint.

Flooding of floors (horizontal areas) was modelled specifically for laminate composite flooring. The work included in the budget consists of mounting and removing laminate floating flooring, baseboards and bottom counterbalance layer. Calculation of costs related to the transport of rubble and material on the construction site was added to the work done on both vertical and horizontal structures. Afterwards, the unit loss for $1 \mathrm{~m}^{2}$ of room floor area was calculated from the resulting amount of total loss.

The prices of work and materials were calculated using the KROS plus budgeting programme with 17.00 price database (ÚRS Praha, 2014). The materials used are at the standard price level: for example, the unit price of a laminate floor is $502 \mathrm{CZK} /$ $\mathrm{m}^{2}$ and the unit price of white antimicrobial paint is $53.70 \mathrm{CZK} / 1$. All prices for work and material are listed without VAT (exchange rate CZK 1 = EUR 0.0365 as of 23 March 2015).

In the next step, loss curves for the individual size groups of the rooms were created in the Excel programme, while the general curve equations and their parameters were determined in the MatLab programme.

Finally, the graphic and numerical results were used to assess the impact of the room dimensions on the amount of loss.

\section{Results and Discussion}

The processing of 422 possible situations created a large data file of unit losses related to $1 \mathrm{~m}^{2}$ of floor area. Thanks to the sufficient number of data, it was possible to represent the data graphically in the form of curves. The curves shown in Fig. 1 represent the dependence of the room side ratios on the amount of unit loss. Altogether, there are 14 curves with each curve representing one room size group.

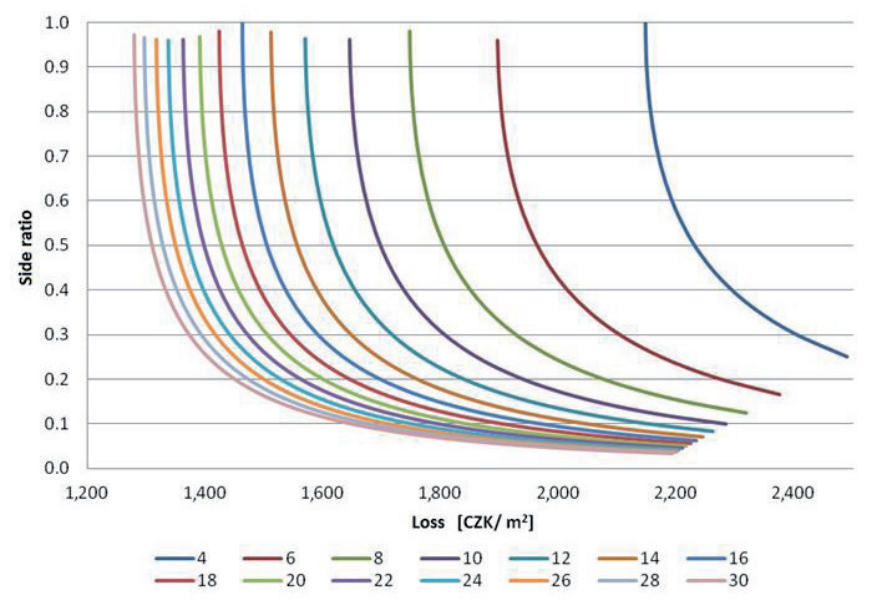

Fig. 1 The amount of unit loss in relation to the room side ratio (depth of flooding $1 \mathrm{~m}$ )

The chart clearly shows that the shape of the room has an impact on the amount of unit loss. The closer the side ration is to 1 , the lower the unit loss and vice versa - the larger the difference between the length and the width of the room, the higher the value of the unit loss. This dependence is valid regardless of the size of the room. The reason is a longer room circumference related to the lower side ratio value; the primary consequence of this is an increase in the areal extent of damage to vertical structures (plaster, paint).

Furthermore, it was ascertained that the room size (measured in floor area $-\mathrm{m}^{2}$ ) also has an impact on unit loss. In general, it holds that the larger the area of the room, the lower the unit size and vice versa. This dependence arises out of the changing proportions of the amount of loss resulting from damage to horizontal and vertical constructions in the total loss.

A general equation of the curve was defined in the MatLab programme to express the relationships between the side ratio and amount of unit loss:

$$
L=\frac{X^{a}+b}{Y^{e}+d}
$$

where: L - loss per $1 \mathrm{~m}^{2}$ of floor area; X - room area; Y - room side ratio; $\mathrm{a}, \mathrm{b}, \mathrm{c}, \mathrm{d}$ - equation parameters (values of equation parameters change depending on the room size group).

However, the essential question is whether the impact of room dimensions (size and shape) on the amount of unit loss and thus also on the accuracy of loss estimation using the loss curve is sufficiently significant. As the loss curve only serves as an estimate, a certain level of inaccuracy is expected. The variability of unit loss values in relation to room dimensions is shown in Table 2.

In the case of smaller rooms, there are larger differences among unit loss values than in the case of larger rooms. For example, in 
Table 2 Difference in unit loss per $\mathrm{m}^{2}$ for different side ratios and size groups

\begin{tabular}{|c|c|c|c|c|c|}
\hline Size group & Room area $\left[\mathrm{m}^{2}\right]$ & Side ratio & Unit loss $\left[\mathrm{CZK} / \mathrm{m}^{2}\right]$ & Comparison level & Increase in unit loss value \\
\hline RG1 & 4 & 1.000 & $2,148.42$ & \multirow[b]{2}{*}{ Base 1} & Base $(100 \%)$ \\
\hline RG1 & 4 & 0.250 & $2,490.65$ & & $116 \%$ \\
\hline RG14 & 30 & 0.243 & $1,409.71$ & \multirow{2}{*}{ Base 2} & Base $(100 \%)$ \\
\hline RG1 & 4 & 0.250 & $2,490.65$ & & $177 \%$ \\
\hline RG14 & 30 & 0.972 & $1,279.41$ & \multirow{4}{*}{ Base 3} & Base $(100 \%)$ \\
\hline RG14 & 30 & 0.243 & $1,409.71$ & & $110 \%$ \\
\hline RG14 & 30 & 0.033 & $2,194.05$ & & $171 \%$ \\
\hline RG1 & 4 & 0.250 & $2,490.65$ & & $195 \%$ \\
\hline
\end{tabular}

RG1 the unit loss value for side ratio 0.25 is $116 \%$ of the unit loss value for side ratio 1.00, while in RG14 the unit loss value for side ratio 0.243 is only $10 \%$ higher than for the side ratio of 0.972. In the case of less usual room dimensions (such as long corridors), the unit loss for a side ratio of 0.033 equals $171 \%$ of the value of a comparison level corresponding to a ratio of 0.972 . And finally, in the extreme case of RG1 and side ratio of 0.25 , the unit loss is $195 \%$ of a comparison level of RG14 and side ratio of 0.971 . Results presented in Table 2 clearly show that the factor of room dimensions have a significant effect on the amount of unit flood loss. Deviations of more than $10 \%$ often occur (as a consequence of different side ratios), in extreme cases (i.e. in the combination of different side ratios and room size groups) reach values of almost $100 \%$. Finally, in can be stated, that the effect room size shows greater significance than the side ratio effect.

\section{Conclusion}

This paper examined the impact of room dimensions on the amount of unit loss resulting from flood damage to residential buildings. Loss curves defined for a model depth of flooding of $1 \mathrm{~m}$ and selected types of vertical and horizontal structures were defined to assess this impact. These curves show the amount of unit loss in relation to the ratio of the room dimensions and its floor area.

The results proved that the room dimensions have an impact on the amount of the unit loss in relation both to the size of the room and to its shape. Moreover, the combination of these two factors may in extreme cases have a fundamental impact on the amount of unit loss.

Therefore, it seems reasonable to take room dimensions into account in loss curves on the level of individual rooms, so that e.g. insurance companies can use this quicker way of evaluation to determine the amount of loss with acceptable accuracy. However, it can be presumed that floods would affect the whole floor, not just one isolated room. Future research will therefore focus not only on modelling different depths of flooding and material specifications, but also on the impact of room dimensions on the amount of unit loss for the whole building.
The research presented in this paper has two main limitations. Firstly, it examines the impact of room dimensions only at a fixed depth of flooding. Secondly, the study omits other flood parameters, such as duration of the flooding. Taking into consideration the interactions of these variables could bring another interesting dimension into the examined area.

\section{Acknowledgement}

The project presented in this article is supported by research grant FAST-J-15-2706 entitled "Refining the Calculation Methodology Used to Determine Damage to Buildings Caused by Floods".

\section{References}

André, C., Monfort, D., Bouzit, M., Vinchon, C. (2013) Contribution of insurance data to cost assessment of coastal flood damage to residential buildings: Insights gained from Johanna (2008) and Xynthia (2010) storm events. Natural Hazards and Earth System Sciences. 13 (8). pp. 2003 2012. DOI: 10.5194/nhess-13-2003-2013

Elmer, F., Thieken, A.H., Pech, I., Kreibich, H. (2010) Influence of flood frequency on residential building losses. Natural Hazards and Earth System Science. 10 (10). pp. 2145-2159. DOI: 10.5194/nhess-10-2145-2010

Glosinska, E. (2014) Floodplain Management in the Context of Assessment and Changes of Flood Risk and the Environment - a Review. Polish Journal of Environmental Studies. 23 (6). pp. 1895-1904.

Grahn, T., Nyberg, R. (2014) Damage assessment of lake floods: Insured damage to private property during two lake floods in Sweden 2000/2001. International Journal of Disaster Risk Reduction. 10. pp. 305-314. DOI: 10.1016/j.ijdrr.2014.10.003

Hanák, T., Korytárová, J. (2014) Risk zoning in the context of insurance: Comparison of flood, snow load, windstorm and hailstorm. Journal of Applied Engineering Science. 12 (2). pp. 137-144. DOI: 10.5937/jaes12-6098

Hattermann, F.F., Huang, S., Burghoff, O., Willems, W., Österle, H., Büchner, M., Kundzewicz, Z. (2014) Modelling flood damages under climate change conditions-a case study for Germany. Natural Hazards and Earth System Sciences. 14 (12). pp. 3151-3169. DOI: 10.5194/nhess-14-3151-2014

Jiang, W., Deng, L., Chen, L., Wu, J., Li, J. (2009) Risk assessment and validation of flood disaster based on fuzzy mathematics. Progress in Natural Science. 19 (10). pp. 1419-1425. DOI: 10.1016/j.pnsc.2008.12.010 
Jongman, B., Koks, E. E., Husby, T. G., Ward, P. J. (2014) Increasing flood exposure in the Netherlands: Implications for risk financing. Natural Hazards and Earth System Sciences. 14 (5). pp. 1245-1255.

DOI: 10.5194/nhess-14-1245-2014

Kelman, I., Spence, R. (2004) An overview of flood actions on buildings. Engineering Geology. 73 (3-4). pp. 297-309.

DOI: $10.1016 /$ j.enggeo.2004.01.010

Kreibich, H., Piroth, K., Seifert, I., Maiwald, H., Kunert, U., Schwarz, J., Merz, B., Thieken, A.H. (2009) Is flow velocity a significant parameter in flood damage modelling? Natural Hazards and Earth System Science. 9 (5). pp. 1679-1692. DOI: 10.5194/nhess-9-1679-2009

Kreibich, H., Thieken, A. H., Petrow, T., Müller, M., Merz, B. (2005) Flood loss reduction of private households due to building precautionary measures - Lessons learned from the Elbe flood in August 2002. Natural Hazards and Earth System Science. 5 (1). pp. 117-126.

DOI: 10.5194/nhess-5-117-2005

Merz, B., Kreibich, H., Thieken, A., Schmidtke, R. (2004) Estimation uncertainty of direct monetary flood damage to buildings. Natural Hazards and Earth System Science. 4 (1). pp. 153-163.

DOI: 10.5194/nhess-4-153-2004

Ružić, I., Marović, I., Benac, Č., Ilić, S. (2014) Coastal cliff geometry derived from structure-from-motion photogrammetry at Stara Baška, Krk Island, Croatia. Geo-Marine Letters. 34 (6). pp. 555-565.

DOI: $10.1007 / \mathrm{s} 00367-014-0380-4$
Sampson, C. C., Fewtrell, T. J., O’loughlin, F., Pappenberger, F., Bates, P. B., Freer, J. E., Cloke, H. L. (2014) The impact of uncertain precipitation data on insurance loss estimates using a flood catastrophe model. Hydrology and Earth System Sciences. 18 (6). pp. 2305-2324. DOI: 10.5194/hess-18-2305-2014

Tingsanchali, T., Karim, F. (2010) Flood-hazard assessment and risk-based zoning of a tropical flood plain: Case study of the Yom River, Thailand. Hydrological Sciences Journal. 55 (2). pp. 145-161. DOI: $10.1080 / 02626660903545987$

ÚRS Praha. Kalkulační a rozpočtovaci program KROS plus 2014. (Calculation and Budgeting Software KROS plus 2014). (in Czech).

Vivoda, M., Benac, Č., Žic, E., Domlija, P., Jovačević, S.D. (2012) Geohazards in the Rječina Valley in the past and present. Hrvatske Vode. 20 (81). pp. 105-116.

Zeleňáková, M., Zvijáková, L. (2014) Environmental impact assessment of flood mitigation measures: Methodology based on risk analysis. WIT Transactions on Ecology and the Environment. 181. pp. 115-124. DOI: 10.2495/EID140101 